\title{
PENGELOMPOKAN KABUPATEN-KOTA DALAM PRODUKSI DAGING TERNAK DI JAWA TENGAH TAHUN 2016 -2018 MENGGUNAKAN METODE MULTIDIMENSIONAL SCALING
}

\author{
Imam Desla Siena', Agus Rusgiyono², Dwi Ispriyanti ${ }^{3}$ \\ ${ }^{1}$ Mahasiswa Jurusan Statistika FSM Universitas Diponegoro \\ ${ }^{2,3}$ Staff Pengajar Jurusan Statistika FSM Universitas Diponegoro \\ Email: agus.rusgi@gmail.com
}

\begin{abstract}
Animal husbandry is very important for the development of the welfare of the people of Central Java.the geographical conditions, Central Java is a suitable place to do livestock activities.Because of the increasing needs of livestock meat on the market, empowerment of livestock can be used as a livelihood to improve the economy of Central Java Comunity. This research is aimed at mapping the production of livestock meat in cities in Central Java both rural and urban areas. This study aimed to map existing health facilities in cities in West Java. The results of the analysis conducted by using Multidimensional Scaling analysis shows how grouping the cities in Central Java by its production of livestock meat. From the mapping of the cities there are three groups that have similarities among its members but different from the other groups.Each group formed have similar characteristics of a number of production of livestock meat.
\end{abstract}

Keywords : Multidimensional Scaling, mapping, Animal husbandry.

\section{PENDAHULUAN}

Jawa Tengah (disingkat Jateng) adalah sebuah provinsi di Indonesia yang terletak di bagian tengah Pulau Jawa. Ibu kotanya adalah Semarang. Provinsi ini berbatasan dengan Provinsi Jawa Barat di sebelah barat, Samudra Hindia dan Daerah Istimewa Yogyakarta di sebelah selatan, Jawa Timur di sebelah timur, dan Laut Jawa di sebelah utara. Letaknya antara $5^{\circ} 40^{\prime}$ dan $8^{\circ} 30^{\prime}$ Lintang Selatan dan antara $108^{\circ} 30^{\prime}$ dan $111^{\circ} 30^{\prime}$ Bujur Timur (termasuk Pulau Karimunjawa). Jarak terjauh dari Barat ke Timur adalah $263 \mathrm{~km}$ dan dari Utara ke Selatan $226 \mathrm{~km}$ (tidak termasuk Pulau Karimunjawa). Luas wilayahnya $32.548 \mathrm{~km}^{2}$, atau sekitar $28,94 \%$ dari luas pulau Jawa. Provinsi Jawa Tengah juga meliputi Pulau Nusakambangan di sebelah selatan (dekat dengan perbatasan Jawa Barat), serta Kepulauan Karimun Jawa di Laut Jawa. Jawa tengah terdiri dari 35 kabupaten/kota.Dengan jumlah 29 pemerintahan Kabupaten dan 6 pemerintahsn kota. Jawa tengah mempunyai jumlah penduduk sebesar 34.490,84 ribu jiwa dan sebesar $42,34 \%$ penduduk ber mata pencaharian yang mengandalkan sektor pertanian dan peternakan. Pertanian dan peternakan merupakan sektor utama perekonomian Jawa Tengah, di mana mata pencaharian di bidang ini digeluti hampir separuh dari angkatan kerja. Peternakan merupakan sektor yang memiliki peluang besar untuk dikembangkan sebagai usaha di masa depan. Kebutuhan masyarakat akan produk produk peternakan semakin meningkat setiap tahunnya. 
terdapat 4 hewan yang mendominasi Produktivitas ternak di jawa tengah, yaitu Sapi potong, kambing, ayam pedaging, itik.Dalam kurun waktu antara tahun 2016 - 2018 ratarata terjadi peningkatan produktivitas hewan ternak di Jawa Tengah.Untuk produktivitas Sapi pada tahun 2016 mencapai 58.168.389 ekor dan mengalami peningkatan sebesar 2,98 \% ditahun 2017 sedangkan di tahun 2018 mengalami peningkatan sebasar 8,1\% dari tahun sebelumnya. Untuk produktivitas Kambing pada tahun 2016 mencapai 11.668.904 ekor dan mengalami peningkatan sebesar 1,62 \% ditahun 2017 sedangkan di tahun 2018 mengalami penurunan sebasar 0,32\% dari tahun sebelumnya. Untuk produktivitas Ayam pedaging pada tahun 2016 mencapai 187.965.015ekor dan mengalami peningkatan sebesar 8,76 \% ditahun 2017 sedangkan di tahun 2018 mengalami peningkatan sebasar 10,09\% dari tahun sebelumnya.Untuk produktivitas itik pada tahun 2016 mencapai 3.379 .730 ekor dan mengalami peningkatan sebesar 7,1\% ditahun 2017 sedangkan di tahun 2018 mengalami peningkatan sebasar $1,1 \%$ dari tahun sebelumnya. ${ }^{11]}$ Oleh karena itu, sebagai pelaku dan penentu kebijakan peternak, pemerintah harus berupaya bersama dalam rangka meningkatkan dan memelihara produktivitas di sektor peternakan. Salah satu upaya yang dapat dilakukan dalam rangka meningkatkan dan memelihara produktivitas di sektor peternakan yaitu dengan mengelompokkan wilayah kabupaten/kota ke dalam kelompokkelompok berdasarkan kesamaan karakteristik yang dimiliki. Pengelompokan ini bertujuan agar informasi terkait jenis ternak yang tersebar di tiap-tiap wilayah kabupaten/kota yang ada menjadi lebih efisien dan spesifik. Sehingga dalam melakukan pembinaan di setiap kelompok daerah dibidang peternakan akan lebih fokus, terarah dan tepat. Salah satu cara untuk pengelompokan ini dapat di identifikasi menggunakan analisis Multidimensional Scaling. Analisis Multidimensional Scalling (MDS) merupakan salah satu teknik statistika yang dapat digunakan untuk menentukan posisi suatu obyek berdasarkan penilaian kemiripannya, juga untuk mengetahui hubungan saling ketergantungan antar variabel atau data. Hubungan ini tidak diketahui melalui pengelompokan variabel, melainkan dengan membandingkan variabel yang ada pada setiap obyek yang bersangkutan dengan menggunakan perceptual map. MDS berhubungan dengan pembuatan peta untuk menggambarkan posisi sebuah obyek dengan obyek lainnya berdasarkan kemiripan obyekobyek tersebut. ${ }^{[2}$

\section{TINJAUAN PUSTAKA}

\subsection{Peternakan}

Peternakan adalah kegiatan mengembangbiakkan dan membudidayakan hewan ternak untuk mendapatkan manfaat dan hasil dari kegiatan tersebut. Kegiatan di bidang peternakan dapat dibagi atas dua golongan, yaitu peternakan hewan besar seperti sapi, kambing, domba dan babi. Sedangkan, kelompok kedua yaitu peternakan hewan kecil seperti ayam, itik dan lain-lain. Kementerian Pertanian terus berupaya dalam mewujudkan kemandirian pangan berbasis agrobisnis rakyat melalui berbagai program unggulan subsektor peternakan. Menyasar peternakan rakyat, pemerintah berupaya meningkatkan produktivitas ternak dengan memperkuat sistem pemeliharaan dan manajemen peternakan secara umum. Berbagai aspek menjadi titik pengendalian program, diantaranya adalah peningkatan kulitas pakan, bibit, kesehatan hewan, pengolahan produk dari hewan serta manajemen usaha. Pembangunan peternakan dan kesehatan hewan telah memberikan pengaruh yang cukup besar terhadap pertumbuhan ekonomi di Jawa Tengah.Hal tersebut dapat dilihat dari beberapa indikator, diantaranya penyerapan tenaga kerja sektor peternakan sebanyak 1.2267 orang lebih, kontribusi subsektor peternakan terhadap PDRB Propinsi Jawa Tengah Tahun 2017 mencapai 2,51 persen, dan Nilai Tukar Petani (NTP) subsektor 
peternakan tahun 2018 berdasarkan Statistik BPS Propinsi jawa Tengah selalu diatas nilai 100. ${ }^{[1]}$

Pada tahun 2018 produksi daging ternak besar di Jawa Tengah untuk sapi, kerbau dan kuda masing-masing sebanyak 64.755,61 ribu, 1.642,74 ribu $\mathrm{kg}$, dan 1,63 ribu $\mathrm{kg}$. Sedangkan produksi daging ternak kecil untuk kambing, domba dan babi masing-masing sebanyak 11.819,85 ribu $\mathrm{kg}, 5.933,90$ ribu $\mathrm{kg}$ dan 560,70 ribu kg. Produksi unggas yaitu ayam kampung 31,40 juta $\mathrm{kg}$, ayam petelur 11,45 juta $\mathrm{kg}$, ayam pedaging 225,05 juta $\mathrm{kg}$, dan itik/itik manila 3,66 juta kg. ${ }^{[1]}$

\subsection{Analis is Multivariat}

Analisis multivariat adalah teknik statistik yang secara bersamaan manganalisis beberapa pengukuran pada individu atau objek yang diselidiki. Analisis multivariat merupakan metode pengolahan variabel dalam jumlah yang banyak, dimana tujuannya adalah untuk mencari pengaruh variabel-variabel tersebut terhadap suatu objek secara serentak. ${ }^{[3]}$ Berdasarkan hubungan antar variabel, analisis multivariat dapat dibedakan menjadi analisis dependensi dan analisis interdepedensi. Analisis dependensi bertujuan untuk menjelaskan nilai variabel tak bebas berdasarkan lebih dari suatu variabel bebas yang mempengaruhi, contoh: regresi berganda, diksriminan, analisis konjoin. Sedangkan analisis interdependensi bertujuan untuk memberikan arti kepada suatu kelompok variabel atau mengelompokkan suatu kelompok variabel menjadi kelompok yang lebih sedikit jumlahnya dan masing-masing kelompok membentuk variabel baru yang disebut faktor (mereduksi jumlah variabel). Contoh: analisis faktor, analisis klaster dan Penskalaan multidimensional scaling. ${ }^{[4]}$

\subsection{Jarak Euclid}

Menurut Wikipedia Indonesia jarak Euclid adalah perhitungan jarak dari 2 buah titik dalam ruang euclidean. Metode Euclidean adalah suatu metode pencarian nilai jarak terdekat dari 2 buah variabel, selain mudah proses ini juga cepat. ${ }^{[2]}$ Kedekatan antar objek pada perceptual map dapat dihitung dengan menggunakan jarak Euclid data rasio dapat dihitung dengan rumus sebagai berikut:

dimana :

$$
d_{(x, y)}=\sqrt{\sum_{j=1}^{n}\left(x_{j}-y_{j}\right)^{2}}
$$

$d_{x, y}:$ jarak antar objek ke-x dan objek ke-y (jarak euclid)

$x_{j}$ : hasil pengukuran objek $\mathrm{x}$ pada variabel ke-j $(\mathrm{j}=1,2,3,4)$ titik di $R^{4}$

$y_{j}$ : hasil pengukuran objek y pada variabel ke-j $(\mathrm{j}=1,2,3,4)$ titik di $R^{4}$

\subsection{Analis is Multidimensional scaling}

Analisis Multidimensional Scalling (MDS) adalah metode analisis multivariat yang menggunakan representasi grafis untuk mendapatkan informasi dari data.Tujuan utama (MDS) adalah memetakan objek objek dalam suatu bidang multidimensi sehingga posisi relatif obyek-obyek dalam bidang tersebut menggambarkan tingkat kedekatan antar obyek yang sebenarnya. Menurut Hair dkk (1998), penskalaan dimensi ganda sering digunakan di bidang pemasaran untuk mengidentifikasi ukuran pokok yang mendasari penilaian konsumen terhadap sebuah produk dan tehadap pelayanan. Pada akhirnya, analisis ini menghasilkan suatu strategi yang dilakukan untuk memasarkan produk dalam kerangka persaingan dengan produk lain. 


\subsection{Jenis-jenis Multidimensional scaling}

Menurut Ahmad (2011) tipe data berdasarkan skala pengukuran dibagi menjadi 4 (empat) tipe, yaitu skala nominal, ordinal, interval dan rasio. Berdasarkan tipe data tersebut, Multidimensional Scaling dibagi menjadi 2 (dua) jenis, yaitu Multidimensional Scaling Metrik dan Multidimensional scaling non Metrik.

\section{Multidimensional Scaling Metrik}

Skala yang digunakan dalam multidimensional scaling metrik adalah skala data interval dan skala data rasio. multidimensional scaling metrik mengasumsikan bahwa data adalah kuantitatif (interval atau rasio). Dalam prosedur multidimensional scaling metrik hanya menyusun bentuk geometri dari titik-titik objek yang diupayakan sedekat mungkin dengan input jarak yang diberikan. Pada dasarnya, MDS metrik adalah mengubah input jarak kedalam bentuk geometrik sebagai outputnya.

\section{Multidimensional Scaling non Metrik}

Multidimesional scaling nonmetrik mengasumsikan bahwa datanya adalah kualitatif (nominal dan ordinal). Pada kasus ini perhitungan kriteria adalah untuk menghubungkan nilai ketidaksamaan suatu jarak ke nilai ketidaksamaan yang terdekat. Program MDS non metrik menggunakan transformasi monoton (sama) kedata yang sebenarnya sehingga dapat dilakukan operasi aritmatika terhadap nilai ketidaksamaannya, untuk menyesuaikan jarak dengan nilai urutan ketidaksamaanya. Transformasi monoton akan memelihara urutan nilai ketidaksamaannya sehingga jarak antara objek yang tidak sesuai dengan urutan nilai ketidaksamaan dirubah sedemikian rupa sehingga akan tetap memenuhi urutan nilai ketidaksamaan tersebut dan mendekati jarak awalnya. Hasil perubahan ini disebut disparities. Disparities ini digunakan untuk mengukur tingkat ketidaktepatan konfigurasi objek-objek dalam peta berdimensi tertentu dengan input data ketidaksamaannya.

\subsection{Nilai STRESS(Standardized Residual Sum of Square )}

Menurut Bilson (2005) Untuk mendapatkan model MDS yang cocok, perlu dilakukan uji validitas MDS. Uji validitas MDS pada hakikatnya adalah proses optimasi dimana validitas tak hanya diuji tapi juga di koreksi melalui beberapa kali iterasi sampai nilai validitasnya relatif terpenuhi. terdapat beberapa kriteria atau pedoman agar hasil yang didapatkan layak dan dapat digunakan untuk interpretasi sesungguhnya yaitu menghitung nilai STRESS (Standardized Residual Sum of Square). Untuk menemukan tingkat ketidakcocokan tersebut maka kita dapat mencari dengan menggunakan rumus nilai STRESS sebagai berikut :

$$
\text { STRESS }=\sqrt{\frac{\left(d_{x y}-\hat{d}_{x y}\right)^{2}}{\left(d_{x y}-\bar{d}\right)^{2}}}
$$

dimana,

$d_{x y}$ : jarak antar objek ke-x dan objek ke-y (jarak euclidean)

$\hat{d}_{x y}:$ jarak yang diperoleh dari peta presepsi

$\bar{d}$ : Rata-rata jarak dalam peta

\section{METODOLOGI PENELITIAN}

Data yang digunakan dalam tugas akhir ini merupakan data sekunder yaitu data Dalam hal ini kita menggunakan data jumlah produksi daging ternak tahun 2016 sampai dengan 
tahun 2018 diambil dari http://jateng.bps.go.id yang tercatat dalam buku "Jawa Tengah dalam Angka" tahun 2017 sampai tahun 2019. Berdasarkan data yang diperoleh terdapat variabel penelitian yang digunakan yaitu variabel Produksi daging ternak.yaitu terdiri dari:

$\mathrm{X} 1$ : Jumlah produksi daging sapi potong

$\mathrm{X} 2$ : Jumlah produksi daging kambing

$\mathrm{X} 3$ : Jumlah produksi daging ayam pedaging

$\mathrm{X} 4$ : Jumlah produksi daging itik

Software yang digunakan sebagai alat hitung adalah SPSS, Microsoft Excel dan Matlab. Adapun langkah-langkah dalam analisis data adalah sebagai berikut:

1. Menentukan nilai kemiripan antar objek ke dalam bentuk matriks jarak $\mathbf{D}$ dengan menggunakan rumus jarak euclid

2. Mencari nilai eigen value dan eigen vector dari matriks $\mathbf{B}$, lalu dipiih 2 nilai eigen value terbesar yang bernilai positif

3. Membuat $m$ dimensi spasial dengan $n$ objek dari koordinat matriks $\mathbf{X}$ dimana $\boldsymbol{X}=$ $\boldsymbol{E}_{\boldsymbol{m}} \boldsymbol{\lambda}_{\boldsymbol{m}}^{\mathbf{1 / 2}}$ dimana $\mathrm{E}_{\mathrm{m}}$ adalah matriks $m$ eigen vectors dan $\boldsymbol{\lambda}_{m}$ merupakan matriks $m$ buah eigenvalues dari $\mathbf{B}$.

4. Mengelompokan hasil dari peta presepsi yang telah terbentuk.

5. Menghitung nilai STRESS

\section{ANALISIS DAN PEMBAHASAN}

\subsection{Hasil Titik koordinat pemetaan}

\section{- Data tahun 2016}

Dari hasil perhitungan pada MATLAB, diperoleh titik-titik stimulus koordinat dalam peta persepsi 2 dimensi. Dapat dilihat pada tabel 1 sebagai berikut:

Tabel 1 Hasil koordinat pemetaan data 2016

\begin{tabular}{lcc}
\hline \multirow{2}{*}{ KOTA/KABUPATEN } & \multicolumn{2}{c}{ KOORDINAT } \\
\cline { 2 - 3 } & 1 & 2 \\
\hline Kab_Cilacap & $-1,4845$ & 0,3084 \\
Kab_Banyumas & $-0,5951$ & $-0,113$ \\
Kab_Purbalingga & $-0,1123$ & 0,1069 \\
Kab_Banjarnegara & 0,1007 & 0,0183 \\
\multicolumn{1}{c}{$\quad \vdots$} & $\vdots$ & $\vdots$ \\
Kota_Pekalongan & 0,4187 & $-0,083$ \\
Kota_Tegal & 0,3879 & 0,0945 \\
\hline
\end{tabular}

\section{- Data tahun 2017}

Dari hasil perhitungan pada MATLAB, diperoleh titik-titik stimulus koordinat dalam peta persepsi 2 dimensi. Dapat dilihat pada tabel 2 sebagai berikut:

Tabel 2 Hasil koordinat pemetaan data 2017

\begin{tabular}{lcc}
\hline \multirow{2}{*}{ KOTA/KABUPATEN } & \multicolumn{2}{c}{ KOORDINAT } \\
\cline { 2 - 3 } & 1 & 2 \\
\hline Kab_Cilacap & $-0,7811$ & 0,1926 \\
Kab_Banyumas & $-0,731$ & $-0,0069$ \\
Kab_Purbalingga & 0,1301 & 0,0426 \\
Kab_Banjarnegara & 0,1332 & 0,003 \\
\multicolumn{1}{c}{$:$} & $\vdots$ & $\vdots$
\end{tabular}




\begin{tabular}{llc} 
Kota_Pekalongan & 0,4619 & $-0,0935$ \\
Kota_Tegal & 0,4343 & 0,0958 \\
\hline
\end{tabular}

\section{- Data tahun 2018}

Dari hasil perhitungan pada MATLAB, diperoleh titik-titik stimulus koordinat dalam peta persepsi 2 dimensi. Dapat dilihat pada tabel 3 sebagai berikut:

\begin{tabular}{lcc}
\multicolumn{2}{c}{ Tabel 3 Hasil koordinat pe metaan data 2018} \\
\cline { 2 - 3 } KOTA/KABUPATEN & \multicolumn{2}{c}{ KOORDINAT } \\
\cline { 2 - 3 } & 0,048 & 0,0502 \\
Kab_Cilacap & $-0,5678$ & $-0,0648$ \\
Kab_Banyumas & 0,3223 & 0,0049 \\
Kab_Purbalingga & 0,2041 & $-0,012$ \\
Kab_Banjarnegara & $\vdots$ & $\vdots$ \\
\multicolumn{1}{c}{$\quad \vdots$} & 0,524 & $-0,0791$ \\
Kota_Pekalongan & 0,4962 & 0,0823 \\
Kota_Tegal & &
\end{tabular}

\subsection{Hasil Grafik Pemetaan}

\section{- Data tahun 2016}

Berdasarkan grafik koordinat stimulus dapat dihasilkan output grafik pemetaan untuk pemetaan produksi daging ternak di seluruh kota/kabupaten di Jawa Tengah adalah sebagai berikut:

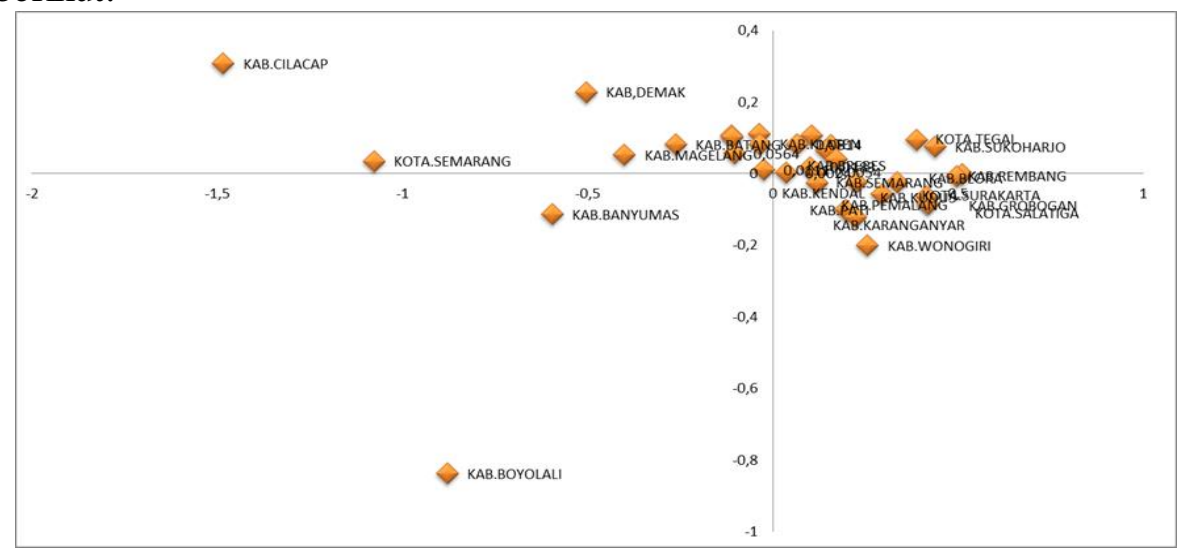

Gambar 1 Grafik pemetaan produksi daging te rnak tahun 2016

Berdasarkan Gambar 1 di atas menunjukan posisi dari 35 Kota/Kabupaten di Jawa Tengah berdasarkan jumlah Produksi daging ternak yang ada pada kota/kabupaten tersebut yaitu produksi daging sapi, produksi daging kambing, produksi daging ayam pedaging dan produksi daging itik pada tahun 2016. Apabila dilihat dari plot secara keseluruhan terdapat empat kelompok kota/kabupaten yang memiliki kemiripan antar anggotanya namun berbeda dengan kelompok lainnya. Keempat kelompok tersebut adalah:

Kelompok 1/Kuadran I (kiri atas): Terdiri dari 11 kota-kabupaten yaitu Kabupaten Cilacap, Kabupaten purbalingga, Kabupaten Wonosobo, Kabupaten Magelang, Kabupaten Demak, Kabupaten Kendal, Kabupaten Batang,Kabupaten Tegal, Kabupaten Brebes,Kota Semarang dan Kota Salatiga. 11 Kabupaten/kota tersebut dipandang memiliki persamaan karakteristik dalam produksi daging ternak yaitu produksi daging itik dan daging kambing karena berada dalam 1 kuadran. 
Kelompok 2/Kuadran II (kanan atas): Terdiri dari 10 kota-kabupaten yaitu Kabupaten Banjarnegara, Kabupaten Kebumen, Kabupaten Purworejo, Kabupaten Sukoharjo, Kabupaten Kudus, Kabupaten Temanggung, Kabupaten Pekalongan, Kabupaten Pemalang, Kota Magelang dan Kota Tegal. 10 Kabupaten/kota tersebut dipandang memiliki persamaan karakteristik dalam produksi daging ternak yaitu produksi ayam potong karena berada dalam 1 kuadran.

Kelompok 3/Kuadran III (kiri bawah): Terdiri dari 2 kabupaten yaitu Kabupaten Banyumas dan Kabupaten Boyolali. 2 Kabupaten tersebut dipandang memiliki persamaan karakteristik dalam produksi daging ternak yaitu produksi daging sapi karena berada dalam 1 kuadran.

Kelompok 4/Kuadran IV (kanan bawah): Terdiri dari 12 kota-kabupaten yaitu Kabupaten Klaten, Kabupaten Wonogiri, Kabupaten Karanganyar, Kabupaten Sragen, Kabupaten Grobogan, Kabupaten Blora, Kabupaten Rembang,Kabupaten Pati, Kabupaten Jepara,Kabupaten Semarang, Kota Surakarta dan Kota Pekalongan. 12 Kabupaten/kota tersebut dipandang memiliki persamaan karakteristik dalam produksi daging ternak yaitu tidak memproduksi daging sapi, daging itik, daging kambing dan daging ayam potong karena berada dalam 1 kuadran.

\section{- Data tahun 2017}

Berdasarkan grafik koordinat stimulus dapat dihasilkan output grafik pemetaan untuk pemetaan produksi daging ternak di seluruh kota/kabupaten di Jawa Tengah adalah sebagai berikut:

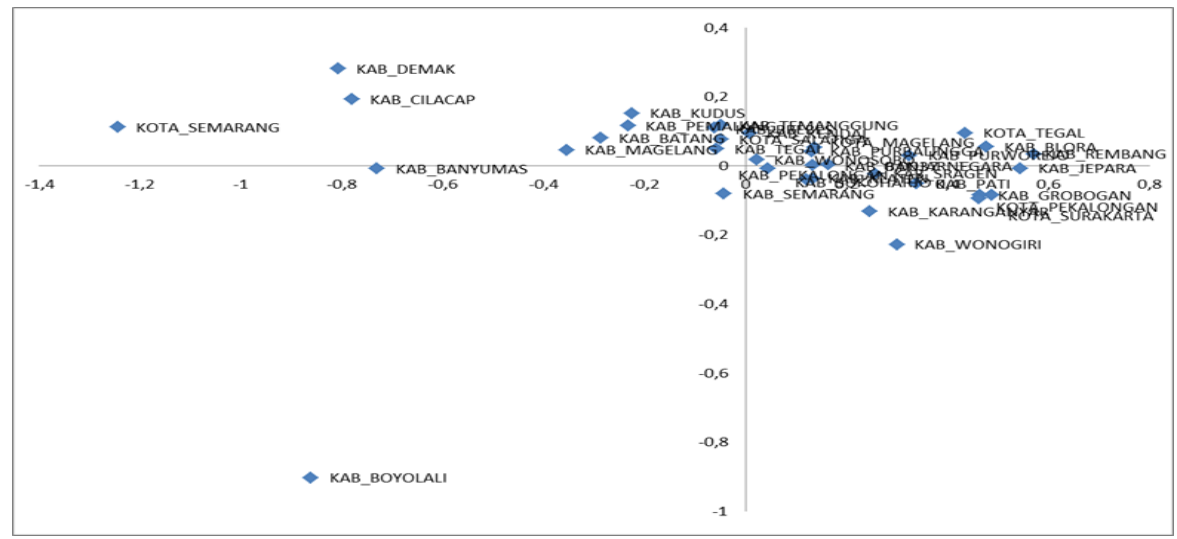

Gambar 2 Grafik pemetaan produksi daging ternak tahun 2017

Berdasarkan Gambar 2 di atas menunjukan posisi dari 35 Kota/Kabupaten di Jawa Tengah berdasarkan jumlah Produksi daging ternak yang ada pada kota/kabupaten tersebut yaitu produksi daging sapi, produksi daging kambing, produksi daging ayam pedaging dan produksi daging itik pada tahun 2017. Apabila dilihat dari plot secara keseluruhan terdapat empat kelompok kota/kabupaten yang memiliki kemiripan antar anggotanya namun berbeda dengan kelompok lainnya. Keempat kelompok tersebut adalah:

Kelompok 1/Kuadran I (kiri atas): Terdiri dari 11 kota-kabupaten yaitu Kabupaten Cilacap, Kabupaten Magelang, Kabupaten Demak, Kabupaten Kudus, Kabupaten Pemalang, Kabupaten Batang, Kabupaten Temanggung, Kabupaten Tegal, Kabupaten Brebes,Kota Semarang dan Kota Salatiga. 11 Kabupaten/kota tersebut dipandang memiliki persamaan karakteristik dalam produksi daging ternak yaitu produksi daging itik dan daging kambing karena berada dalam 1 kuadran. 
Kelompok 2/Kuadran II (kanan atas): Terdiri dari 10 kota-kabupaten yaitu Kabupaten purbalingga, Kabupaten Wonosobo, Kabupaten Banjarnegara, Kabupaten Kebumen, Kabupaten Purworejo, Kabupaten Blora, Kabupaten Rembang, Kabupaten Kendal, Kota Magelang dan Kota Tegal. 10 Kabupaten/kota tersebut dipandang memiliki persamaan karakteristik dalam produksi daging ternak yaitu produksi ayam potong karena berada dalam 1 kuadran.

Kelompok 3/Kuadran III (kiri bawah): Terdiri dari 3 kabupaten yaitu Kabupaten Banyumas, Kabupaten Semarang dan Kabupaten Boyolali. 2 Kabupaten tersebut dipandang memiliki persamaan karakteristik dalam produksi daging ternak yaitu produksi daging sapi karena berada dalam 1 kuadran.

Kelompok 4/Kuadran IV (kanan bawah): Terdiri dari 11 kota-kabupaten yaitu Kabupaten Klaten, Kabupaten Wonogiri, Kabupaten Sukoharjo, Kabupaten Karanganyar, Kabupaten Sragen, Kabupaten Grobogan, Kabupaten Blora, Kabupaten Pekalongan, Kabupaten Pati, Kabupaten Jepara, Kota Surakarta dan Kota Pekalongan. 12 Kabupaten/kota tersebut dipandang memiliki persamaan karakteristik dalam produksi daging ternak yaitu tidak memproduksi daging sapi, daging itik, daging kambing dan daging ayam potong karena berada dalam 1 kuadran.

\section{- Data tahun 2018}

Berdasarkan grafik koordinat stimulus dapat dihasilkan output grafik pemetaan untuk pemetaan produksi daging ternak di seluruh kota/kabupaten di Jawa Tengah adalah sebagai berikut:

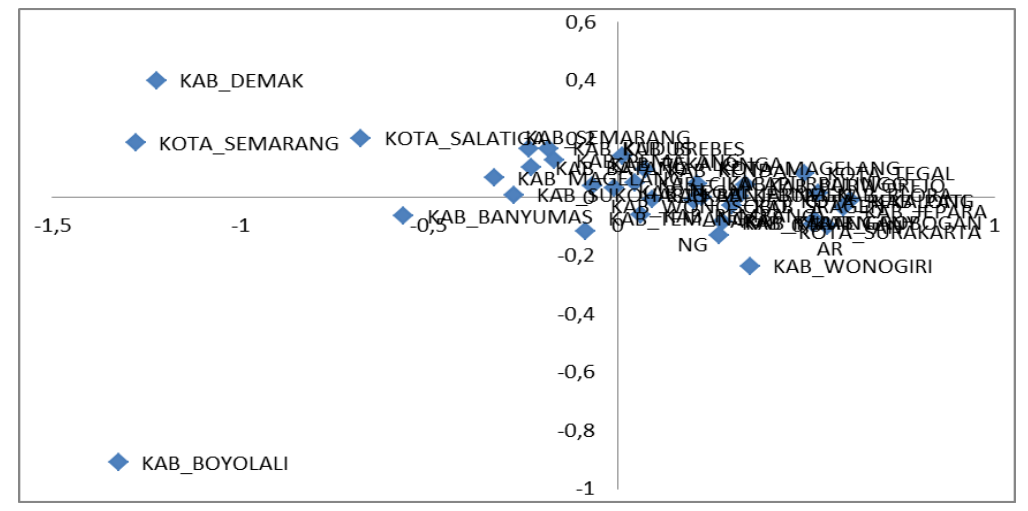

Gambar 3 Grafik pemetaan produksi daging ternak tahun 2018

Berdasarkan Gambar 3 di atas menunjukan posisi dari 35 Kota/Kabupaten di Jawa Tengah berdasarkan jumlah Produksi daging ternak yang ada pada kota/kabupaten tersebut yaitu produksi daging sapi, produksi daging kambing, produksi daging ayam pedaging dan produksi daging itik pada tahun 2018. Apabila dilihat dari plot secara keseluruhan terdapat tiga kelompok kota/kabupaten yang memiliki kemiripan antar anggotanya namun berbeda dengan kelompok lainnya. Ketiga kelompok tersebut adalah:

. Kelompok 1/Kuadran I (kiri atas): Terdiri dari 11 kota-kabupaten yaitu Kabupaten Wonosobo, Kabupaten Magelang, Kabupaten Sukoharjo, Kabupaten Kudus, Kabupaten Demak, Kabupaten Semarang, Kabupaten Batang, Kabupaten Pemalang, Kabupaten Tegal, Kota Semarang dan Kota Salatiga. 11 Kabupaten/kota tersebut dipandang memiliki persamaan karakteristik dalam produksi daging ternak yaitu produksi daging itik dan daging kambing karena berada dalam 1 kuadran.

Kelompok 2/Kuadran II (kanan atas): Terdiri dari 8 kota-kabupaten yaitu Kabupaten Cilacap, Kabupaten Purbalingga, Kabupaten Purworejo, Kabupaten Blora, Kabupaten 
Kendal, Kabupaten Brebes, Kota Magelang dan Kota Tegal. 8 Kabupaten/kota tersebut dipandang memiliki persamaan karakteristik dalam produksi daging ternak yaitu produksi ayam potong karena berada dalam 1 kuadran.

Kelompok 3/Kuadran III (kiri bawah): Terdiri dari 3 kabupaten yaitu Kabupaten Banyumas, Kabupaten Temanggung dan Kabupaten Boyolali. 3 Kabupaten tersebut dipandang memiliki persamaan karakteristik dalam produksi daging ternak yaitu produksi daging sapi karena berada dalam 1 kuadran.

Kelompok 4/Kuadran IV (kanan bawah): Terdiri dari 13 kota-kabupaten yaitu Kabupaten Banjarnegara, Kabupaten Kebumen, Kabupaten Klaten, Kabupaten Wonogiri, Kabupaten Karanganyar, Kabupaten Sragen, Kabupaten Grobogan, Kabupaten Rembang, Kabupaten Pati, Kabupaten Jepara, Kabupaten Pekalongan, Kota Surakarta dan Kota Pekalongan. 13 Kabupaten/kota tersebut dipandang memiliki persamaan karakteristik dalam produksi daging ternak yaitu tidak memproduksi daging sapi, daging itik, daging kambing dan daging ayam potong karena berada dalam 1 kuadran.

\subsection{Menghitung Nilai STRESS}

Untuk mendapatkan model MDS yang cocok, perlu dilakukan uji validitas MDS. Terdapat beberapa pedoman agar hasil yang didapatkan layak dan dapat digunakan untuk interpretasi sesungguhnya yaitu menghitung nilai STRESS (Standardized Residual Sum of Square). Nilai STRESS dapat dicari menggunakan bantuan SPSS dengan hasil sebagai berikut:

\section{- Data tahun 2016}

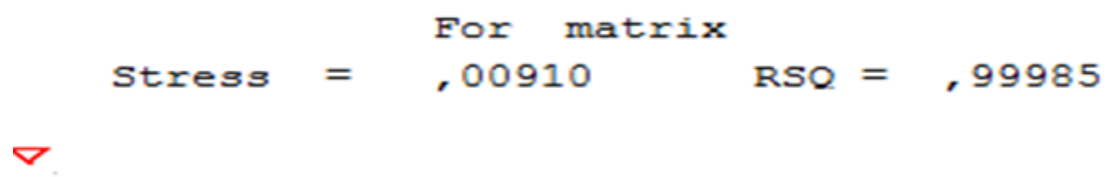

Dari hasil output di atas di dapat nilai stress adalah sebesar 0,00910 atau 0,91\% berdasarkan pedoman kriteria masuk ke dalam sempurna. Artinya bahwa model dapat diterima untuk mengambarkan pemetaan 35 Kota/Kabupaten di Jawa Tengah berdasarkan jumlah produksi daging ternak pada tahun 2016.

- Data tahun 2017

$$
\text { Stress }=, \text { For matrix }
$$

Dari hasil output di atas di dapat nilai stress adalah sebesar 0,00942 atau 0,942\% berdasarkan pedoman kriteria masuk ke dalam sempurna. Artinya bahwa model dapat diterima untuk mengambarkan pemetaan 35 Kota/Kabupaten di Jawa Tengah berdasarkan jumlah produksi daging ternak pada tahun 2017

- Data tahun 2018

$$
\text { Stress }=, \text { For matrix }
$$


Dari hasil output di atas di dapat nilai stress adalah sebesar 0,00711 atau 0,711\% berdasarkan pedoman kriteria masuk ke dalam sempurna. Artinya bahwa model dapat diterima untuk mengambarkan pemetaan 35 Kota/Kabupaten di Jawa Tengah berdasarkan jumlah produksi daging ternak pada tahun 2018

\section{KESIMPULAN}

Berdasarkan hasil dan pembahasan penerapan Multidimensional Scalling pada Produksi daging ternak di Jawa Tengah pada tahun 2016 - 2018, dapat disimpulkan bahwa :

1. Berdasarkan data Pada tahun 2016 dapat disimpulkan bahwa tiap Kabupaten/Kota ada kesamaan karakteristik dalam hal produksi daging ternak yang terbagi menjadi 4 kelompok. Sedangkan untuk nilai STRESS adalah sebesar 0,00910 atau 0,91\% berdasarkan pedoman kriteria masuk ke dalam sempurna. Artinya bahwa model dapat diterima untuk mengambarkan pemetaan $35 \mathrm{Kota} /$ Kabupaten di Jawa Tengah berdasarkan jumlah produksi daging ternak pada tahun 2016.

2. Berdasarkan data pada tahun 2017 dapat disimpulkan bahwa tiap Kabupaten/Kota ada kesamaan karakteristik dalam hal produksi daging ternak yang terbagi menjadi 4 kelompok. Sedangkan untuk nilai STRESS adalah sebesar 0,00942 atau 0,942\% berdasarkan pedoman kriteria masuk ke dalam sempurna. Artinya bahwa model dapat diterima untuk mengambarkan pemetaan $35 \mathrm{Kota} /$ Kabupaten di Jawa Tengah berdasarkan jumlah produksi daging ternak pada tahun 2017.

3. Berdasarkan data Pada tahun 2018 dapat disimpulkan bahwa tiap Kabupaten/Kota ada kesamaan karakteristik dalam hal produksi daging ternak yang terbagi menjadi 4 kelompok. Sedangkan untuk nilai STRESS adalah sebesar 0,00711 atau 0,711\% berdasarkan pedoman kriteria masuk ke dalam sempurna. Artinya bahwa model dapat diterima untuk mengambarkan pemetaan 35 Kota/Kabupaten di Jawa Tengah berdasarkan jumlah produksi daging ternak pada tahun 2018.

\section{DAFTAR PUSTAKA}

[1] [BPS].Badan Pusat Statistik Kota Semarang. 2018."Semarang Barat dalam angka

2015".Semarang

http://semarangkota.bps.go.id/index.php/en/Jawatengahdalamangka2019. (diakses 25

November 2019 pukul 19.00 WIB).

[2] Ginanjar, I. 2008. Aplikasi Multidimensial Scaling untuk Produk Pada

Masalah Product Existing. Di dalam: Prosiding Seminar Nasional Matematika dan Statistika 2008, Surabaya

[3] Jhonson, R , and Dean W. 2007. Applied Multivariate Data Analysis

7th Edition. Upper Saddle River. New jersey. Prentice-Hall .

[4] Mardia K, Kent J and Bibby J. 1979. Multivariate Analysis.London: ACADEMIC PRESS

Harcourt Brace \& Company.

[5] Nahar, J. 2016. Penerapan Metode Multidimensial Scaling dalam Pemetaan Sarana Kesehatan di Jawa Barat, Bandung.

[6] Supranto, J. 2010. Analisis Multivariat Arti dan Interpretasi. Jakarta: Rineka Cipta.

[7] Simamora, B. 2005. Analisis Multivariat Pemasaran. Jakarta: PT Gramedia Pustaka Utama.

[8] Timm, N. H. , 2002. Applied Multivariate Analysis. New York : Springer-Verleg. 